\title{
Organic or Local? Investigating Consumer Preference for Fresh Produce Using a Choice Experiment with Real Economic Incentives
}

\author{
Chengyan Yue ${ }^{1,3}$ \\ University of Minnesota-Twin Cities, Horticultural Science \& Applied \\ Economics, 1970 Folwell Avenue, St. Paul, MN 55108
}

Cindy Tong ${ }^{2}$

University of Minnesota-Twin Cities, Horticultural Science, St. Paul, MN 55108

Additional index words. hypothetical experiment, hypothetical bias, tomatoes, willingness to pay, marketing

\begin{abstract}
Determining consumers' preferences and willingness to pay (WTP) for organically grown and locally grown fresh produce is very important for stakeholders because it helps them figure out what type of fresh produce to grow and sell, what to emphasize in marketing efforts, and what are reasonable prices to charge. However, the literature that studies and compares consumers' preference and WTP for both organically and locally grown fresh produce is sparse. The objective of this study was to investigate consumers' WTP for organically grown and locally grown fresh produce and the marketing segmentation of these two types of produce. We combined a hypothetical experiment and nonhypothetical choice mechanism to investigate consumers' WTP for the attributes organic, local, and organic plus local for fresh produce. We found that when real products were used in the hypothetical experiment, the hypothetical bias (the difference between what people say they will pay and what they would actually pay) was not high. We found that consumers' WTP for the organic attribute was about the same as their WTP for the local attribute. Consumers' sociodemographics affected their choice between organically grown and locally grown produce. Furthermore, we found that consumers patronized different retail venues to purchase fresh produce with different attributes. The findings of the research have great importance for fresh produce stakeholders to make correct production and marketing decisions; the findings also contribute to experimental method choice in consumers' WTP research.
\end{abstract}

Intense competition from large-scale growers has forced small-scaled farmers to find new niche markets for their commodities through value-added marketing. To discover the right niche market is a complicated task because demand is highly segmented among consumers who may be concerned with different attributes such as local, organic, and other specialty types. A recent survey of 500 Twin Cities consumers showed that consumers buy locally grown produce primarily because of its high quality and freshness (King, 2007). Previous studies that focused on consumers' choices at farmers' markets in other states showed that today's

Received for publication 31 Oct. 2008. Accepted for publication 13 Jan. 2009.

We gratefully acknowledge the support from the Office of the Dean of the Graduate School of the University of Minnesota.

We thank Paul Hugunin from Minnesota Department of Agriculture for his support of the study.

${ }^{1}$ Assistant Professor and Bachman Endowed Chair in Horticultural Marketing.

${ }^{2}$ Associate Professor.

${ }^{3}$ To whom reprint requests should be addressed; e-mail yuechy@umn.edu. consumers support local farmers' markets because they expect higher quality (for example, freshness and taste) and lower prices (Brown, 2002, 2003). Organically grown produce is considered to be healthy and environmentally friendly because of the use of less-damaging pesticides (Magnusson et al., 2001; Thompson and Kidwell, 1998). For some consumers, premium price is the major obstacle in buying organic foods (Magnusson et al., 2001).

Yet, "locally grown" produce is not necessarily "organically grown" produce. Locally grown produce can be produced using conventional production methods. Organic produce purchased by Minnesota consumers might be from California or New Zealand. Finding out why certain consumers prefer organically grown or locally grown produce and their willingness to pay (WTP) for fresh produce with different attributes is important for stakeholders such as producers and marketers in making their production and marketing decisions because it helps them figure out what type of fresh produce to grow and sell, what to emphasize in marketing efforts, and what are reasonable prices to charge. The literature on consumer preferences for and marketing segmentation of organically and locally grown fresh produce is sparse. Loureiro and Hine (2002) studied consumers' WTP for local (Colorado-grown), organic, and GMO-free potatoes. They found that the "Colorado-grown" attribute afforded potato producers the highest consumer acceptance and premium compared with organic and GMO-free potatoes. However, only consumers' attitudes toward potato freshness and nutrition were included in their estimation. Important consumer attitudes toward certain quality attributes such as appearance, taste, food safety, and so on (Yue et al., 2007, 2008) were not included in their study.

The traditional hypothetical survey method is preferred by most academic researchers in consumer preference studies. The hypothetical method asks individuals to choose the values they are willing to pay for certain products without asking them to exchange money and real goods. Although widely used, a question about this approach that has been aroused is whether values elicited from hypothetical experiments reflect the amounts individuals would actually pay. It is well documented that consumers are less reluctant to spend money in stated preference studies than in markets with real economic commitment. In the literature, this is known as the hypothetical bias (see, for example, Alfnes et al., 2006). Previous studies also show that there is significant hypothetical bias when consumers' WTP is elicited using pictures instead of real products in hypothetical studies in which participants do not need to pay for the products shown in the pictures (see, for example, Yue et al., 2008). Lusk and Schroeder (2004) found that there is no significant difference between marginal WTP elicited from hypothetical and nonhypothetical experiments when real products instead of pictures are used in both experiments.

The objective of this study was to investigate consumers' WTP for organically grown and locally grown fresh produce and the marketing segmentation of these two types of produce. The results of this research are very important for small-scale farmers, market organizers, and sponsoring agencies in making their production and marketing decisions. This study also contributes to the literature on consumers' choice and demand segmentation between organically grown and locally grown produce. In addition, our research is different from previous studies in that we used and compared two methods to investigate consumer preference for and WTP for organically and locally grown fresh produce. We used both the traditional hypothetical experiment and the nonhypothetical experiment with real economic incentives. The use of a choice format is new in the consumer preference and WTP literature. Lusk and Schroeder (2004) developed the choice format with posted prices in different scenarios to investigate consumers' WTP for food quality attributes. Alfnes et al. (2006) used a nonhypothetical choice experiment to investigate consumers' WTP for salmon with different colors. The hypothetical experiment and nonhypothetical choice experiment with 
real economic incentives give data in similar formats and are complimentary to each other; one gives hypothetical WTP data and the other gives real WTP data. The use of the two methods helps eliminate the hypothetical bias that exists in traditional hypothetical experimental methods and get consumers' real WTP for fresh produce with different attributes.

\section{Materials and Methods}

We tested the data from the hypothetical experiment and the nonhypothetical choice experiment for similarities and used the two data sources in a joint estimation. We tested if the use of real products instead of pictures can eliminate hypothetical bias. The details of both experiments are presented subsequently.

Attributes. The fresh produce used for the study was tomatoes because they are widely grown locally and organically in Minnesota. In our experimental design, there were two qualitative attributes (organically grown and locally grown) and one quantitative attribute (price). Each qualitative attribute had two levels - yes or no. The number of levels for the quantitative factor, price, was six. The price ranged from $\$ 1.25$ to $\$ 2.50$ with $\$ 0.25$ as intervals based on real tomato prices in different stores in the Twin Cities area when the experiments were conducted. Table 1 summarizes the levels of attributes.

There were four combinations of the two qualitative attributes as shown in Table 2. In our experiment, we named the locally grown (no) and organically grown (no) as "conventional," locally grown (no) and organically grown (yes) as "organic," locally grown (yes) and organically grown (no) as "local," and locally grown (yes) and organically grown (yes) as "organic + local."

The tomatoes were purchased from a farmers' market, a supermarket, and an organic farm in St. Paul, MN. Other product attributes such as tomato size, color, shape, size, firmness, and ripeness were not included in the design. However, the tomatoes were of the same type and when we made purchases, we carefully compared tomatoes' color, size, shape, ripeness, and firmness to make them be very similar to each other in these attributes. Therefore, the tomatoes' possible differences in these attributes were controlled and participants said that they were unable to distinguish between them.
Scenarios. In the hypothetical and nonhypothetical experiments, participants were presented with a series of pricing scenarios and asked to choose one alternative in each pricing scenario. If none of the alternatives was of interest, they could choose "none of these." To lessen the cognitive burden on participants, only two alternatives were usually included in each scenario in a choice experiment. In our experiments, each scenario had two alternatives described by conventional, organic, local, or organic plus local attributes and price. Because it was not practical to ask each participant to choose from all possible scenarios, a fractional factorial design was developed to minimize scenario number and maximize profile variation. The design was developed based on four principles: level balance (levels of an attribute occurred with equal frequency), orthogonality (the occurrences of any two levels of different attributes were uncorrelated), minimal overlap (cases in which attribute levels did not vary within a scenario were minimized), and utility balance (the probabilities of choosing alternatives within a scenario were kept as similar as possible) (Louviere et al., 2000). The fractional factorial design gave each participant sets of 12 scenarios to evaluate. The clearly dominated alternatives were eliminated. For a further discussion of factorial design, see Louviere et al. (2000).

The following is an example of one of the scenarios:

Please examine the tomatoes on the table. Consider a situation in which you are buying $1 \mathrm{lb}$ of fresh tomatoes. From the following pairs of alternatives, please choose one alternative that you would like to purchase (you can choose "none" if you do not want either of them): Scenario 1 - conventional $\$ 1.75$; organic + local $\$ 2.25$; none of these.

Next to organic tomatoes, we put a USDA Certified Organic label; beside local tomatoes, we put a Minnesota Grown label; and beside locally grown, organic tomatoes, we put both the USDA Certified Organic label and the Minnesota Grown label.

Hypothetical experiment. For the hypothetical experiment, participants were not asked to buy anything after they made choices. Real products were used in the hypothetical experiment. Participants were asked to answer a series of questions such as what kind of retailers they were most likely to patronize and a series of questions designed

Table 1. Fresh produce attributes and the attribute levels tested in this study.

\begin{tabular}{lcccccc}
\hline Attributes & Level 1 & Level 2 & Level 3 & Level 4 & Level 5 & Level 6 \\
\hline Organically grown & No & Yes & - & - & - & - \\
Locally grown & No & Yes & - & - & - & - \\
Price & $\$ 1.25$ & $\$ 1.50$ & $\$ 1.75$ & $\$ 2.00$ & $\$ 2.25$ & $\$ 2.50$ \\
\hline
\end{tabular}

Table 2. The combinations of the two qualitative attributes tested in this study.

\begin{tabular}{llll}
\hline \multirow{2}{*}{ Name of the alternatives in the experiments } & & \multicolumn{2}{c}{ Organically grown } \\
\cline { 3 - 4 } Locally grown & No & "Conventional" & "Organic" \\
& Yes & "Local" & "Organic + local" \\
\hline
\end{tabular}

to extract information on their attitudes toward and preference for the organic and local attributes of fresh produce.

Nonhypothetical experiment. For the nonhypothetical choice experiment, one of the pricing scenarios was randomly drawn as binding, i.e., the choices made in that scenario would be implemented. Participants would receive the products they chose and were required to pay the prices posted for the corresponding products in the binding scenario. The nonhypothetical choice experiment had the following five steps-Step 1: The experimental procedure was explained to participants and some information about the alternatives (the three attributes) was provided. Step 2: Participants studied the alternatives in scenarios and marked on a choice scheme which of the alternatives in each scenario they wanted to buy. Step 3: After participants completed all scenarios, each participant drew one card with a number determining his or her binding scenario. Step 4: Each participant received the fresh produce he or she chose in his or her binding scenario. Step 5: Participants went to the cashier and paid for their fresh produce. After participants made their choices, they were asked to answer the same set of questions as in the hypothetical experiment.

Sampling. A booth was set up at the Minnesota State Fair to conduct the hypothetical and the nonhypothetical choice experiments in Aug. 2008. The Minnesota Sate Fair is the largest U.S. state fair in terms of average daily attendance (Minnesota State Fair, 2008). The sociodemographics of fair attendees are close to Minnesotan sociodemographics except that a slightly higher proportion of those aged between 35 and 44 years attend the Fair who live in Minnesota (Minnesota State Fair, 2008; U.S. Census Bureau, 2004). Therefore, we expected to get a representative sample of Minnesota consumers. State Fair participants were randomly selected to participate in the experiments. Each participant only participated in one type of experiment, either the hypothetical experiment or the nonhypothetical experiment. A small amount of cash or gifts worth $\$ 6$ to $\$ 8$ was given to participants to compensate for their time. To ensure that the sample was representative, only one family member per household was allowed to participate in the experiments. Most participants at the Minnesota State Fair came as families. When we recruited participants, we asked the primary food purchaser of the household to participate in the experiments. In total, 365 participants were surveyed with 115 participating in the nonhypothetical experiment and the remaining 250 participating in the hypothetical experiment. Some of the data were not included in the analysis because of one or more missing values. Observations of 343 participants with 110 participants from the nonhypothetical experiment and 233 from the hypothetical experiment were included in the analysis.

Statistical model. Consumers' satisfaction derived from choice and consumption of dif- 
ferent produce relied on measurable factors, including consumers' characteristics and their preferences for the attributes conventional, local and organic. Consumer characteristics included were age, gender, education level, income, household size, if there were children in the household, and if they were from an urban or rural area. Because the dependent variable was categorical (whether the alternative was chosen by participants), we used a mixed logit model to estimate the probability of a consumer's choice of certain fresh produce. The logit model and multinomial logit model are widely used to estimate consumers' choice of different products or stores (see for example, Yue and Behe, 2008). Different from the standard logit model, the mixed logit model allows correlation in factors (Train, 2003). We used the mixed logit model to capture all possible correlations for responses from the same participant and scenario. The statistical model was:

$$
U_{n i s}=\beta^{\prime} x_{n i s}+\eta^{\prime}+\varepsilon_{n i s}
$$

where $U_{n i s}$ was the utility of individual $n$ from alternative $i$ in scenario $s$; $x_{\text {nis }}$ were vectors of observed variables relating to alternative $i$ and individual $n ; \beta$ was a vector of fixed coefficients; $\eta$ was a vector of normally distributed random terms with mean zero used to capture the possible correlations; and $\epsilon_{\text {nis }}$ was an identical and independent extreme value error term. The standard logit model is a special case of the mixed logit model where $\eta$ has zero variance.

The density of $\eta$ was denoted by $f(\eta \mid \Omega)$, where $\Omega$ was the fixed parameter vector of the distribution. For a given $\eta$, the conditional choice probability of alternative $i$ was a standard logit:

$$
L_{i}(\eta)=\frac{e^{\beta^{\prime} x_{i}+\eta^{\prime}}}{\sum_{j \in J} e^{\beta^{\prime} x_{j}+\eta^{\prime}}}
$$

Consequently, the unconditional choice probability, $P$, in the mixed logit model was the logit formula integrated overall values of $\eta$ with density of $\eta$ as weights:

$$
P_{i}=\int L_{i}(\eta) f(\eta \mid \Omega) d \eta
$$

This integral should be solved analytically and was approximated through simulation (Brownstone and Train, 1999).

The maximum likelihood estimation method was used to estimate coefficients with Stata 10.0 software (StataCorp, College Station, TX).

\section{Results and Discussion}

The summary statistics of the sample are shown in Table 3 . Approximately $84.51 \%$ of participants purchased fruits and vegetables more than once a week and only $0.28 \%$ of participants purchased fruits or vegetables less than once a month. These results, derived from the data, indicated that the sample of participants was representative of consumers

\begin{tabular}{|c|c|c|c|}
\hline Variables & Description of variables & Mean & SD \\
\hline$\overline{\text { Often }}$ & $\begin{array}{l}\text { How often do you buy fruits or vegetables? } \\
1=\text { Once a week }(84.51 \%)^{\mathrm{y}} \\
2=\text { Two or three times a month }(9.30 \%)^{\mathrm{y}} \\
3=\text { Once a month }(2.82 \%)^{\mathrm{y}} \\
4=\text { Only when in season }(3.10 \%)^{\mathrm{y}} \\
5=\text { Never or less than once a month }(0.28 \%)^{\mathrm{y}}\end{array}$ & 1.32 & 0.79 \\
\hline Envir & $\begin{array}{l}\text { Do you belong to any groups associated with environment? } \\
1=\text { yes, } 0=\text { no }\end{array}$ & 0.23 & 0.42 \\
\hline $\operatorname{Age}^{z}$ & Participant's age & 45.03 & 13.07 \\
\hline Urban & Do you live in an urban area or rural area? $1=$ urban, $0=$ rural & 0.73 & 0.45 \\
\hline Child & Do you have children under $12 ? 1=$ yes, $0=$ no & 0.14 & 0.35 \\
\hline Edu & $\begin{array}{l}\text { What is the highest level of education you have completed? } \\
1=\text { Some high school or less }(1.13 \%)^{\mathrm{y}} \\
2=\text { High school diploma }(6.20 \%)^{\mathrm{y}} \\
3=\text { Some college }(20.00 \%)^{\mathrm{y}} \\
4=\text { College diploma }(33.24 \%)^{\mathrm{y}} \\
5=\text { Some graduate school }(9.58 \%)^{\mathrm{y}} \\
6=\text { Graduate degree }(29.86 \%)^{\mathrm{y}}\end{array}$ & 4.33 & 1.31 \\
\hline Gender & Gender of participant, $1=$ male, $0=$ female & 0.34 & 0.47 \\
\hline Household & Number of people in the household & 2.45 & 1.18 \\
\hline Income $^{\mathrm{z}}$ & $\begin{array}{l}\text { Income of participants }(\$ 1000) \\
\text { What type of stores did you buy most of your fresh fruits } \\
\text { and vegetables from in } 2007 ?^{x}\end{array}$ & 69.34 & 28.93 \\
\hline Mass & Mass merchandiser & 0.09 & 0.29 \\
\hline Coop & Cooperatives & 0.11 & 0.31 \\
\hline Special & High-end specialty stores & 0.16 & 0.37 \\
\hline Super & Supermarket & 0.68 & 0.47 \\
\hline Discount & Discount stores & 0.07 & 0.26 \\
\hline Farmer & Roadside stand and farmers' market & 0.27 & 0.45 \\
\hline
\end{tabular}
who are regular fresh produce consumers.

Table 3. Summary statistics of the sample.

${ }^{\mathrm{z}} \mathrm{Age}$ and income were in categories in the original data. The midpoints in each category were used to convert age and income to continuous variables.

${ }^{\mathrm{y}}$ The numbers in parentheses were the percentages of participants who belong to the corresponding categories.

xParticipants were told to choose all that applied.

The average age of participants was 45 years old. Seventy-three percent of participants lived in urban areas and $23 \%$ of them belonged to certain environmental groups. Fourteen percent of participants had children younger than 12 years old in the household, $66 \%$ of participants were female, and the average education level was a college degree. On average, there were two to three people in a household and the average income level was $\approx \$ 69,000$. A large proportion of participants $(68 \%)$ purchased most of their fresh produce from supermarkets, $27 \%$ from a roadside stand or farmers' market, $16 \%$ from high-end specialty stores, $11 \%$ from cooperatives, $9 \%$ from mass merchandisers, and $7 \%$ from discount stores.

In the questionnaire, we also asked participants how important certain characteristics of locally grown and organically grown fresh produce were to their purchase decision using a Likert scale with 1 being not important and 5 being very important. The percentage of participants who considered different characteristics at various levels of importance are listed in Tables 4 and 5. The characteristics were chosen based on previously published studies (Loureiro and Hine, 2002; King, 2007; Yue et al., 2007, 2008).

For locally grown fresh produce, $83 \%$ of participants considered freshness as "very important" and $72 \%$ of them rated safe to eat as "very important." Forty-eight percent of participants thought lower price "somewhat important" and $17 \%$ of them regarded it as "very important." Supporting the local econ- omy was a good reason for people to choose locally grown fresh produce as indicated by the fact that $74 \%$ of participants chose 4 or 5 on the Likert scale. Environmentally friendly was also considered to be important for $61 \%$ of participants. Carbon footprint was a concern for $54 \%$ of participants, whereas $25 \%$ of participants did not regard it as a major concern.

For organically grown fresh produce, $52 \%$ of participants considered good for health to be "very important" and $26 \%$ of them thought it to be "important" (they chose 4 ). Forty percent of them regarded lower price as "somewhat important" and $42 \%$ of them chose 4 or 5 , which means that these people thought that lower price was "important" or "very important" for organic fresh produce. Approximately $83 \%$ of participants thought safe to eat as "important" or "very important" for organic fresh produce and $67 \%$ of them considered environmentally friendly as "important" or "very important." These results were consistent with previous studies showing that consumers associate organic production methods with a reduced health risk and may choose to reduce the risk from pesticide residues by switching to organically grown products (Magnusson and Cranfield, 2005; Williams and Hammitt, 2001). Recent survey evidence shows that consumers purchased organic foods because they perceived the foods to be fresh (68.3\%), better for health, and a better source of nutrition (67.1\%; Whole Foods Market, 2005). Furthermore, over $70.3 \%$ of the con- 
Table 4. The percentages of consumers who rated the importance of different characteristics in their decision of whether to purchase locally grown fresh produce.

\begin{tabular}{|c|c|c|c|c|c|}
\hline & Not important & & Somewhat important & & Very important \\
\hline & 1 & 2 & 3 & 4 & 5 \\
\hline Freshness & 1.13 & 0.28 & 2.25 & 13.52 & 82.82 \\
\hline Lower price & 3.38 & 10.70 & 47.89 & 20.85 & 17.18 \\
\hline Safe to eat & 1.97 & 1.69 & 7.32 & 17.18 & 71.83 \\
\hline Support local economy & 1.69 & 5.08 & 18.93 & 33.05 & 41.24 \\
\hline Carbon footprint & 14.74 & 14.16 & 25.14 & 23.99 & 21.97 \\
\hline Environmentally friendly & 3.98 & 8.81 & 26.14 & 32.95 & 28.13 \\
\hline
\end{tabular}

Table 5. The percentages of consumers who rated the importance of different characteristics in their decision of whether to purchase organically grown fresh produce.

\begin{tabular}{|c|c|c|c|c|c|}
\hline & Not important & & Somewhat important & & $\underline{\text { Very important }}$ \\
\hline & 1 & 2 & 3 & 4 & 5 \\
\hline Good for health & 4.83 & 3.41 & 14.20 & 25.85 & 51.70 \\
\hline Lower price & 8.00 & 9.71 & 40.00 & 24.00 & 18.29 \\
\hline Safe to eat & 3.72 & 2.87 & 10.60 & 22.06 & 60.74 \\
\hline Environmentally friendly & 4.30 & 6.88 & 22.06 & 30.37 & 36.39 \\
\hline
\end{tabular}

sumers said they bought organic food or beverages to avoid pesticides.

To get some idea of participants' past purchases of locally grown and organically grown produce, we asked participants "When you buy fruits and vegetables, how often do you buy locally grown (organically grown) fresh produce when locally grown (organically grown) options are available?" For locally grown produce, $14 \%$ of participants chose "always," $40 \%$ chose "most times," $38 \%$ chose "sometimes," and 8\% chose "seldom" or "never." For organically grown produce, 6\% chose "always," $15 \%$ chose "most times," 39\% chose "sometimes," and $40 \%$ chose "seldom" or "never."

The estimation results of the mixed logit model are shown in Table 6 . The $P$ value for the likelihood ratio test was $<0.01$, which indicated that the model fit the data well. Although some variables have a naturally interpretable metric, others do not, especially ordinal variables and interaction effects (McCall, 2001). Therefore, to simplify interpretation of parameters associated with the quality attributes, variables except organic, local, price, and real and the associated interaction effects among them were standardized with a mean of zero and a SD of one. The standardization was done by subtracting the respective variable's mean and dividing by its SD. We found that the $P$ values for the correlations among the scenarios and the responses from the same participant were pretty large $(>0.95)$. Therefore, the correlations were deemed to be highly insignificant.

Price premium for local and organic attributes. The intercept and coefficients of organic, local, price, and organic*local were highly significant. The negative sign of the coefficient of price indicated that the higher the price of the product, the lower the proba- bility that participants would be likely to choose the product. The intercept divided by the coefficient of price is the consumer WTP for $1 \mathrm{lb}$ of conventional tomatoes and the amount was $\$ 1.18$. The coefficient of organic divided by that of price is the premium the consumer was willing to pay for 1 lb of organic tomatoes, which was $\$ 0.72$. Similarly, the premium for the local attribute was $\approx \$ 0.73$. The premium for locally grown, organic tomatoes was not the sum of the two premiums, which was indicated by the highly significant negative coefficient of organic*local. Instead, the premium was $\$ 1.16$ (the sum of coefficients of organic, local, and organic*local divided by the coefficient of price).

Hypothetical bias. The marginal significant coefficients of real*price $(P=0.09)$ indicates that there might exist hypothetical bias for the WTP elicited using the hypothetical experiment compared with the nonhypothetical choice experiment. By calculation, we found that the hypothetical bias for organic attributes was $\approx 7.5 \%$ of the premium elicited using the nonhypothetical choice experiment. The hypothetical bias for the premium of the local attribute was $\approx 9 \%$ of the premium elicited using the nonhypothetical choice experiment. Relative to the $\$ 1.16$ premium for the local plus organic attribute in the hypothetical experiment, participants were willing to pay a premium of $\$ 1.07$ for $1 \mathrm{lb}$ of locally grown, organic tomatoes in the nonhypothetical choice experiment. In this respect, our results are in line with the large literature on hypothetical bias in valuation studies. Previous studies have shown that the difference between the real and hypothetical study is not fixed with the changes in WTP (Yue et al., 2008). Some previous studies have found that hypothetical bias is quite high when pictures are used in a hypothetical

Table 6. Maximum likelihood estimation results of consumer choice of conventional, local, and organic tomatoes.

\begin{tabular}{|c|c|c|c|c|c|c|c|}
\hline Variable & Coefficient & $\mathrm{SD}$ & $P$ value & Variable & Coefficient & SD & $P$ value \\
\hline Intercept & $4.272 * * *$ & 0.300 & $<0.01$ & Envir & $-0.151 * * *$ & 0.051 & $<0.01$ \\
\hline Organic & $2.616 * * *$ & 0.422 & $<0.01$ & Envir*organic & $0.142 * * *$ & 0.043 & $<0.01$ \\
\hline Local & $2.649 * * *$ & 0.427 & $<0.01$ & Envir*local & $0.194 * * *$ & 0.046 & $<0.01$ \\
\hline Price & $-3.624 * * *$ & 0.121 & $<0.01$ & Urban & $-0.152 * * *$ & 0.046 & $<0.01$ \\
\hline Local*organic & $-1.053 * * *$ & 0.132 & $<0.01$ & Urban*local & $0.186 * *$ & 0.095 & 0.05 \\
\hline Real & 0.473 & 0.300 & 0.11 & Urban*organic & $0.296 * * *$ & 0.090 & $<0.01$ \\
\hline Real*price & $-0.280 *$ & 0.170 & 0.09 & Mass & $0.190 * * *$ & 0.045 & $<0.01$ \\
\hline Age & 0.014 & 0.047 & 0.77 & Coop & $-0.266 * * *$ & 0.061 & $<0.01$ \\
\hline Age*organic & $-0.367 * * *$ & 0.114 & $<0.01$ & Special & 0.015 & 0.056 & 0.79 \\
\hline Age*local & 0.180 & 0.120 & 0.14 & Super & $0.156 * * *$ & 0.055 & $<0.01$ \\
\hline Income & -0.052 & 0.048 & 0.28 & Discount & 0.037 & 0.042 & 0.39 \\
\hline Income*organic & $0.177 * * *$ & 0.087 & 0.04 & Farm & $-0.147 * * *$ & 0.048 & $<0.01$ \\
\hline Income*local & 0.095 & 0.092 & 0.30 & Mass*organic & $-0.133 * * *$ & 0.037 & $<0.01$ \\
\hline Edu & $0.098 * *$ & 0.047 & 0.04 & Coop*organic & $0.308 * * *$ & 0.047 & $<0.01$ \\
\hline Edu*organic & $-0.189 *$ & 0.106 & 0.08 & Special*organic & 0.036 & 0.048 & 0.45 \\
\hline Edu*local & $-0.203^{*}$ & 0.112 & 0.07 & Super*organic & $-0.138 * *$ & 0.067 & 0.04 \\
\hline Gender & 0.024 & 0.046 & 0.60 & Discount*organic & $-0.091 * * *$ & 0.035 & $<0.01$ \\
\hline Gender*organic & 0.004 & 0.042 & 0.92 & Farm*organic & 0.016 & 0.041 & 0.70 \\
\hline Gender*local & $-0.087 * *$ & 0.045 & 0.05 & Mass*local & $-0.111 * * *$ & 0.040 & $<0.01$ \\
\hline Child & -0.080 & 0.057 & 0.16 & Coop*local & $0.145 * * *$ & 0.050 & $<0.01$ \\
\hline Child*organic & 0.018 & 0.046 & 0.70 & Special*local & -0.001 & 0.051 & 0.97 \\
\hline Child*local & 0.074 & 0.049 & 0.13 & Super*local & $-0.186 * * *$ & 0.072 & 0.01 \\
\hline Household & 0.078 & 0.058 & 0.18 & Discount*local & 0.028 & 0.039 & 0.47 \\
\hline Household*organic & -0.055 & 0.087 & 0.53 & Farm*local & $0.271 * * *$ & 0.045 & $<0.01$ \\
\hline Household*local & 0.017 & 0.091 & 0.85 & & & & \\
\hline
\end{tabular}

***Significant at the $1 \%$ level; **significant at the $5 \%$ level; and *significant at the $10 \%$ level. 
experiment compared with a nonhypothetical experiment using real products (see, for example, Alfnes, 2003; Harrison and Rutström, 2005; Yue et al., 2008). In contrast, we found that hypothetical bias was not that high when real products were used in the hypothetical experiment. The results indicated that even if hypothetical bias might not be completely eliminated as found by Lusk and Schroeder (2004), it can be significantly decreased when real products were used to elicit consumer WTP for certain attributes in a hypothetical experiment. The findings have very important implications for future studies on consumers' WTP literature. Nonhypothetical experiments should be used; if the employment of a nonhypothetical experiment is not practical, real products rather than pictures of products should be used to lower any possible hypothetical bias.

Sociodemographic background of consumers. We found that consumers' sociodemographic backgrounds affected their choice and WTP for conventional, organic, local, or locally grown, organic tomatoes. The interaction effect between age and organic was significant and negative, which indicated that older participants were less likely to choose organic tomatoes compared with younger participants. Older participants were more likely to purchase local tomatoes compared with younger participants, but the coefficient was not highly significant $(P=0.13)$. The significant and positive coefficient of income* organic meant that wealthier participants were more likely to purchase organic tomatoes. This result was in line with other studies on organic attributes of fruits and vegetables (see, for example, Yue et al., 2008). The coefficient of gender*local was significant and negative, which means that female participants were more likely to purchase locally grown tomatoes compared with male participants. In the questionnaire, we asked participants if they belonged to any groups associated with the environment. The estimation results showed that those participants who belonged to environmental groups were least likely to purchase conventional tomatoes and were most likely to purchase locally grown tomatoes followed by organic tomatoes. These results were similar to those by Yue et al. (2007), in that consumers who belonged to environmental groups were more likely to purchase organic apples. Participants' educational backgrounds affected their choice of tomatoes with different attributes. Participants with higher educational levels were more likely to purchase conventional tomatoes and less likely to purchase organic tomatoes. Participants who live in urban areas were most likely to purchase organic tomatoes followed by locally grown tomatoes and were least likely to purchase conventional tomatoes compared with participants from rural areas. One possible explanation is that consumers who live in urban areas may be less likely to grow fresh produce than those who live in rural areas. People experienced with growing products know that there is not as large a quality difference between locally produced fruits and nonlocally produced fruits compared with those who have no growing experience (Yue et al., 2007). Hartman (1997) also showed that the consumption of organic food was skewed in urban areas.

We found that household size did not significantly differentiate participants in their choice of tomatoes with different attributes. However, participants with children younger than age 12 years had a higher chance of choosing locally grown tomatoes even if the coefficient was not highly significant $(P$ value was $\approx 0.13$ ). Also, these participants were more likely to choose organic tomatoes and less likely to choose conventional tomatoes as indicated by the positive sign of the coefficient of child*organic and the negative sign of the coefficient of child, even if the estimated coefficients were not statistically significant.

Store categories. The estimation results showed that participants bought different types of tomatoes from different types of stores. Participants who purchased most fresh produce from mass merchandisers were most likely to choose conventional tomatoes, less likely to choose locally grown tomatoes, and least likely to choose organic tomatoes. Participants who purchased fresh produce mainly from cooperatives had the highest probability of purchasing organic tomatoes, followed by locally grown tomatoes, and they had the lowest probability of purchasing conventional tomatoes. Participants who bought the most fresh produce from specialty stores were more likely to purchase organic tomatoes and less likely to purchase locally grown tomatoes, but the results were not statistically significant. Those participants who often patronize supermarkets were most likely to purchase conventional tomatoes, followed by organic tomatoes, and they were least likely to purchase locally grown tomatoes. Participants who visited discount stores most often were less likely to purchase organic tomatoes. Those participants who often patronized roadside stands and farmers' markets were most likely to purchase locally grown tomatoes, less likely to purchase organic tomatoes, and least likely to choose conventional tomatoes.

Marketing implications. These results have important marketing implications for fresh produce growers, wholesalers, and retailers. A large proportion of consumers consider "freshness" and "safe to eat" as "very important" for purchasing locally grown fresh produce, which indicates that these attributes should be stressed by local growers when they promote their products in advertisements, newsletters, and so on. As for organic fresh produce, "good for health" and "safe to eat" are their selling points and should be emphasized in promotional materials. There exists a group of consumers who view "lower price" as important for local and organic fresh produce, which was consistent with findings of previous studies that premium price was the major obstacle to buying organic foods for some consumers (Magnusson et al., 2001). To promote to this price-sensitive segment, emphasis on "affordability" by decreasing the price premium to a certain level will work to increase sales of organic and local fresh produce. The sociodemographics of consumers who choose conventional, local, or organic attributes have important implications for choices of target markets for fresh produce with differentiated attributes. Older female consumers with lower than average education levels who shop in urban markets are the right target market to promote locally grown fresh produce, whereas younger consumers with above-average income who live in urban areas are the main target market for organic produce.

The average price premiums for organic, local, and organic plus local attributes of tomatoes were $\$ 0.67, \$ 0.67$, and $\$ 1.06$, respectively, compared with conventional tomatoes after correction of hypothetical bias. These price premiums give growers guidelines when they decide what prices to charge for tomatoes with different attributes. Comparing prices that growers, wholesalers, and retailers actually charge with these premiums can provide these parties with information about whether their charged prices were consistent with consumers' perceptual values of these different attributes. Based on this information, the associated parties can make adjustments on their pricing strategies to attract more potential consumers. Finding out these price premiums can also help growers choose the right production methods and profitable value-added attributes to promote by comparing the premiums with the associated production and marketing costs. Interestingly, we found that the average premiums consumers were willing to pay for organic tomatoes and locally grown tomatoes were about the same. However, the profitability of the two types of produce might not be the same as a result of variation in production costs. Local growers can get a higher premium if they grow organic tomatoes and promote them as both locally grown and organically grown instead of organically grown alone in local markets.

The results show that consumers actually patronize different stores to buy fresh produce with different attributes. Therefore, growers and wholesalers need to choose the right stores to sell their products, and retailers need to source the right types of produce for these parties to make profits. Mass merchandisers and supermarkets are the major places consumers purchase conventional produce, which means that conventional fresh produce growers need to choose these retail outlets as their major venues to sell their products. Cooperatives are where most consumers purchase organic produce, indicating that organic fresh produce growers might be able to sell more of their products and can charge a relatively higher price if they choose to sell their products at cooperatives. In contrast, discount stores and mass merchandisers where people expect to get low-priced products are not the major place for growers to sell organic produce. Supermarkets might 
be another choice for selling organic fresh produce. For locally grown fresh produce, consumers are most likely to purchase them from farmers' markets and roadside stands. These direct marketing channels are the best venues for local growers to sell their products. Cooperatives are also good venues to sell locally grown products, whereas mass merchandisers and supermarkets might not be able to gain enough profits by selling locally grown fresh produce.

From the supply perspective, the availability of organic and locally grown produce in different stores also contributes to consumer patronage of these stores in purchasing fresh produce with different attributes. Fresh produce provides the greatest chances for direct sales to consumers through farmers' markets and roadside stands that are commonly used by small-scale growers. Given the fact that most local growers are small scale in Minnesota, it is not surprising that consumers are most likely to choose direct marketing channels to purchase locally grown produce. The growth of organic food has given rise to new marketing outlets in addition to traditional organic outlets such as cooperatives. Mass market groceries and chain stores entered the organic market place at a time of low prices for commodities at the farm gate. However, it has been documented that approximately one third of organic products are sold through mass market grocery stores with a disproportionately higher percentage of processed food and dairy products instead of fresh produce (Klonsky, 2000). In recent years, some mass merchandisers like Walmart started to source and advertise organic fresh produce and they could get a significant market share if they are able to keep prices low enough (Business Week, 2006)

The hypothetical and nonhypothetical experiments were conducted at the Minnesota State Fair. One issue to consider is whether the results are representative of consumers in general (Mitchell and Carson, 1989). In our survey, the sample chosenthose who participated in the Minnesota State Fair-does not necessarily represent all fresh produce consumers in the United States, and in this regard, there is some population choice bias. The "often" variable indicated that most of participants were regular fresh produce consumers, so we expect the sample selection bias to be minor. We thus view our sample respondents as representing a population of the central Midwest instead of representing the total U.S. population. Given the potential biases, the extrapolation of our findings to other populations should be made with caution. We interpret the findings relative to the population attending local and regional fairs and markets.

\section{Conclusions}

To assist small- and medium-sized growers who want to capitalize on growth in demand for differentiated produce, this article presents consumer WTP for the organic, locally grown, and locally grown organic attributes, the characteristics consumers perceive as important when they make purchase decisions of these differentiated fresh produce, and the various types of retail venues where consumers purchase these different products. A combination of the traditional hypothetical experimental method and nonhypothetical choice experiment was used to investigate consumer preference for valueadded fresh produce. The combination of these two methods can help eliminate any possible hypothetical bias in the hypothetical experimental method. We found that hypothetical bias existed using the hypothetical experimental method, but the bias was not high if real products were used in that survey. We elicited consumer WTP for local and organic attributes for fresh tomatoes. We found consumers perceived various characteristics as important for their purchase decision of organic and local fresh produce. Consumers' sociodemographic backgrounds affected their choice of fresh produce with different attributes and consumers patronized different types of stores to purchase conventional, organic, and local fresh produce.

\section{Literature Cited}

Alfnes, F. 2003. Willingness to pay for quality in experimental auction markets and stated choice surveys, Agr. Univ. Norway, As, Norway. Doctoral Scientiarum Theses 18.

Alfnes, F., A. Guttormsen, G. Steine, and K. Kolstad. 2006. Consumers' willingness to pay for the color of salmon: A choice experiment with real economic incentives. Amer. J. Agr. Econ. 88:1050-1061.

Brown, A. 2002. Farmers' market research 19402000: An inventory and review. Amer. J. Altern. Agr. 17:167-176.

Brown, C. 2003. Consumers' preferences for locally produced food: A study in southeas Missouri. Amer. J. Altern. Agr. 18:213-224.

Brownstone, D. and K. Train. 1999. Forecasting new product penetration with flexible substitution patterns. J. Econom. 89:109-129.

Business Week. 2006. Wal-Mart's organic offensive. 16 Feb. 2009. <http://www.businessweek. com/bwdaily/dnflash/mar2006/nf20060329_ 6971.htm>.

Hartman, H. 1997. The evolving organic marketplace. Hartman and New Hope Group, Bellevue, WA.

King, R. 2007. Consumer attitudes about local foods. Home Grown Economy: Foods from Local Farms as an Economic Development Tool conference, University of Minnesota, Morris, Apr. 2007.

Klonsky, K. 2000. Forces impacting the production of organic foods. Agr. Human Values 17:233-243.
Loureiro, L.M. and S. Hine. 2002. Discovering niche markets: A comparison of consumer willingness to pay for local (Colorado grown), organic, and GMO-free products. J. Agr. Appl. Econ. 34:477-487.

Louviere, J.J., D.A. Hensher, and J.D. Swait. 2000. Stated choice methods: Analysis and application. Cambridge University Press, Cambridge, MA.

Lusk, J.L. and T.C. Schroeder. 2004. Are choice experiments incentive compatible? A test with quality differentiated beef steaks. Amer. J. Agr. Econ. 86:467-482.

Magnusson, E. and J.A.L. Cranfield. 2005. Consumer demand for pesticide free food products in Canada: A probit analysis. Can. J. Agr. Econ. 53:67-81.

Magnusson, M.K., A. Arvola, U.K. Hursti, L. Åberg, and P. Sjödén. 2001. Attitudes towards organic foods among Swedish consumers. Br. Food J. 103:209-226.

McCall, R.B. 2001. Fundamental statistics for the behavioral sciences. 8th ed. Wadsworth Publishing, Belmont, CA.

Minnesota State Fair. 2008. Press Room. 15 Nov. 2008. <http://www.mnstatefair.org/pages/press_ room.html>

Mitchell, R.C. and R.T. Carson. 1989. Using surveys to value public goods: The contingent valuation method. Resources for the Future, Washington, DC.

Thompson, G.D. and J. Kidwell. 1998. Explaining the choice of organic produce: Cosmetic defects, prices, and consumer preferences. Amer. J. Agr. Econ. 80:277-287.

Train, K. 2003. Discrete choice methods with simulation. Cambridge University Press, Cambridge, UK.

U.S. Census Bureau. 2004. Selected social characteristics. 16 Feb. 2009. <http://factfinder.census.gov/ servlet/ADPTable?_bm=y\&-qr_name=ACS 2004_EST_G00_DP2\&-geo_id=01000US\&-ds name=ACS_2004_EST_G00_\&-_lang=en\&caller $=$ geoselect\&-redoLog=false\&-format $>$.

Whole Foods Market. 2005. Nearly two-thirds of Americans have tried organic foods and beverages. Press release, 18 Nov. 2005. 16 Feb. 2009. $<\mathrm{http}: / /$ www.wholefoodsmarket.com/pressroom/ 2005/11/18/nearly-two-thirds-of-americans-havetried-organic-foods-and-beverages $>$.

Williams, P.R.D. and J.K. Hammitt. 2001. Perceived risks of conventional and organic produce: Pesticides, pathogens, and natural toxins. Risk Anal. 21:319-330.

Yue, C., F. Alfnes, and H.H. Jensen. 2008. Discounting spotted apples: Investigating consumers' willingness to accept cosmetic damage in an organic product. J. Agr. Appl. Econ. (in press).

Yue, C. and K.B. Behe. 2008. Estimating US consumers' choice of floral retail outlets. HortScience 43:764-769.

Yue, C., H.H. Jensen, D.S. Mueller, G.R. Nonnecke, and M.L. Gleason. 2007. Estimating consumers' valuation of organic and cosmetically damaged apples. HortScience 42:1366-1371. 